\title{
PENERAPAN METODE ABC TERHADAP PENGENDALIAN PERSEDIAAN BAHAN BAKU PADA UD. MAYONG SARI PROBOLINGGO
}

\author{
Junaidi \\ Universitas Panca Marga Probolinggo \\ Email: junaidi_msi@yahoo.co.id
}

\begin{abstract}
U.D Mayong Sari Kabupaten Probolinggo is a business engaged in the manufacture of food especially bread which has existed for 25 years was established on augst 181991 by Mr. Mayong Efendi. UD. Mayong Sari previously not using the ABC method in classifying thu use of raw materias. ABC method of inventory control is a technique by observing groups of goods according to the level of importance of each group of goods. Group items in ABC Analisis based on the total value of sales in a year. The purpose of this study was to determine the classification or types of raw materials what is included in group $A, B, C$ in the $A B C$ analysis. with $A B C$ method can be known raw materials with the highest invesment, medium, and low turnover of the raw marerial based on usage. Type of row material product umit is made up of nine types of components. Based on the results if the data then these components can be categorized in three catagories: category A, category B, and category $C$. Of the nin types of componentse calculated, based on Table 3, then those in category A are 2 types of components ie flour and butter because the cumulative percentage of absorption of funds is less than or equal to $80 \%$, whereas the cumulative percentage item items of goods less than or more than $20 \%$, category B amounts to 2 types of components ie sugar and beans Both types of components because the cumulative percentage item type of goods less than or more than 30\%, and 5 types of components included in category C, namely Stem Milk, Chocolate bar, Egg, Strawbery Jam and Banana, the five components are classified $C$ class which has a cumulative percentage item type of goods more than 50\%.. Wherein category A class is the most importand raw material in the production process, the control needs to be looked at more.
\end{abstract}

Keywords: control supplies, ABC method, Inventory

\begin{abstract}
ABSTRAK
UD. Mayong Sari Kabupaten Probolinggo adalah usaha yang bergerak dibidang makanan khususnya pembuatan roti yang sudah eksis selama 25 tahun didirikan pada tanggal 18 Agustus 1991. UD. Mayong Sari sebelumnya belum menggunakan metode ABC dalam pengklasifikasian penggunaan bahan baku. Pengelompokan barang dalam ABC Analysis berdasarkan total nilai penjualan dalam setahun. Tujuan dari penelitian ini adalah untuk mengetahui klasifikasi atau jenis-jenis bahan baku apa saja yang termasuk kelompok $\mathrm{A}, \mathrm{B}$, dan $\mathrm{C}$ dalam analisis $\mathrm{ABC}$. Dengan metode $\mathrm{ABC}$ ini dapat diketahui bahan baku dengan investasi tertinggi, sedang dan terendah serta perputaran bahan baku tersebut berdasarkan pemakaiannya. Berdasarkan hasil olah data maka komponen-komponen tersebut dapat dikategorikan dalam 3 kategori yaitu: kategori A, kategori B dan kategori C. Dari 9 jenis komponen yang dihitung, maka yang masuk dalam kategori A berjumlah 2 jenis komponen yakni tepung dan mentega karena persentase kumulatif penyerapan dana kurang dari atau sama dengan $80 \%$, sedangkan presentase kumulatif item jenis barang kurang dari atau lebih dari 20\%, kategori B berjumlah 2 jenis komponen yakni gula dan kacang. Kedua jenis komponen karena presentase kumulatif item jenis barang kurang dari atau lebih dari 30\%, dan 5 jenis komponen yang masuk dalam kategori C yaitu Susu batang, Coklat batang, Telur, Selai strawbery dan Pisang, kelima komponen tersebut dikategorikan kelas C yakni yang memiliki persentase kumulatif item jenis barang lebih dari $50 \%$. Dimana kategori kelas A merupakan bahan baku yang paling penting dalam proses produksi, maka pengendaliannya perlu diperhatikan secara lebih.
\end{abstract}

Kata kunci: pengendalian persediaan, metode $\mathrm{ABC}$, persediaan 


\section{JURNAL EKONOMI DAN MANAJEMEN \\ P-ISSN: 2598-9022/ E-ISSN: 2598-9618 \\ Available at:}

http://e-journal.unipma.ac.id/index.php/capital

\section{A. LATAR BELAKANG}

Pada era globalisasi ini dimana dunia usaha tumbuh dengan pesat, seorang pengusaha lebih dituntut untuk bekerja dan berproduksi dengan lebih efisien dalam menghadapi persaingan yang lebih ketat untuk menjaga kelangsungan dan tujuan usaha bisnisnya yakni laba, dalam proses pencapaian tujuan tersebut akan dipengaruhi oleh berbagai faktor,salah satu faktor itu ialah manajemen persediaan bahan baku, menurut Prasetyawan dan Nasution (2008:113) bahan baku adalah barang-barang yang dibeli dari pemasok (supplier) dan akan digunakan atau diolah menjadi produk jadi yang akan dihasilkan oleh perusahaan. Sehingga perusahaan harus memiliki manajemen yang baik agar perusahaan mampu memperoleh laba yang optimal, dengan cara menerapkan suatu kebijakan manajemen dengan memperhitungkan persediaan bahan baku yang optimal untuk menentukan seberapa besar persediaan bahan baku yang sesuai agar tidak menimbulkan pemborosan biaya bahan baku yang tidak terlau banyak maupun tidak terlalu sedikit. Selain dari itu persediaan bahan baku mempunyai pengaruh pada fungsi pemasaran dan keuangan dalam operasi bisnis untuk pengendalian persediaan bahan baku dan penekanan biaya.

Persediaan bahan baku yang optimal dapat memperlancar proses produksi dan penekanan biaya pada produk harus bias menjamin efektifitas dan efisiensi dari pemasaran pada suatu waktu tertentu, Menurut Bahagia (2006:7) persediaan adalah suatu sumber daya menganggur (idle resources) yang keberadaannya menunggu proses lebih lanjut. Yang dimaksud proses lebih lanjut disini dapat berupa kegiatan produksi seperti dijumpai pada sistem manufaktur, kegiatan pemasaran seperti yang dijumpai pada sistem distribusi, ataupun kegiatan konsumsi seperti dijumpai pada sistem rumah tangga, perkantoran dan sebagainya. Oleh karena itu persediaan bahan baku merupakan salah satu kekayaan 


\section{JURNAL EKONOMI DAN MANAJEMEN \\ P-ISSN: 2598-9022/ E-ISSN: 2598-9618 \\ Available at: \\ http://e-journal.unipma.ac.id/index.php/capital}

perusahaan atau salah satu faktor yang memiliki peranan penting dalam sebuah perusahaan untuk mendukung keseimbangan proses produksi dan tujuan perusahaan.

Setiap perusahaan harus mengelola persediaan bahan baku pada perusahaan yang akan menimbulkan berbagai macam biaya, seperti biaya pembelian, biaya pemesanan,serta biaya penyimpanan. Dengan adanya biaya-biaya tersebut diperlukan adanya pengendalian persediaan yang memiliki fungsi untuk menyediakan persediaan yang sesuai dengan biaya yang minimal, sehingga persediaan memiliki peranan penting dalam hal menunjang kebutuhan rencana produksi untuk proses pada waktu yang akan datang. Oleh karena itu dalam sebuah perusahaan harus dapat mempertahankan persediaan bahan baku agar dapat melakukan proses produksi dengan lancar serta yang terpenting adalah dapat memenuhi permintaan konsumen.

Pengadaan bahan baku itu sendiri merupakan titik awal dari pengendalian persediaan, jika titik awal ini sudah tidak tepat, maka pengendalian akan sulit dikontrol atau dikendalikan. Menurut Indrajit dan Djokopranoto (2003), manajemen persediaan (inventory control) atau pengendalian tingkat persediaan adalah kegiatan yang berhubungan dengan perencanaan, pelaksanaan, dan pengawasan penentuan kebutuhan material sedemikian rupa sehingga di satu pihak kebutuhan operasi dapat dipenuhi pada waktunya dan dipihak lain investasi persediaan material dapat ditekan secara optimal. Persediaan bahan baku harus dapat memenuhi kebutuhan rencana produksi, masalah penentuan besarnya persediaan merupakan masalah yang penting bagi perusahaan sebab bahan baku merupakan salah satu faktor yang menjamin kelancaran proses produksi.

Menurut Heizer dan Render (2010:84) metode ABC merupakan metode yang berguna dalam memfokuskan perhatian manajemen penentuan jenis barang yang paling penting dan perlu di prioritaskan 


\section{JURNAL EKONOMI DAN MANAJEMEN \\ P-ISSN: 2598-9022/ E-ISSN: 2598-9618 \\ Available at: \\ http://e-journal.unipma.ac.id/index.php/capital}

dalam persediaan. Sedangkan menurut Prasetyawan dan Nasution (2008 : 236) dalam analisis ABC, persediaan suatu perusahaan dibagi menjadi 3 klasifikasi, yaitu: A, B dan $\mathrm{C}$ sehingga dikenal sebagai analisis ABC. Analisis ABC membagi persediaan dalam tiga kelas berdasarkan atas nilai (volume) persediaan. Kriteria masing-masing kelas dalam analisis $\mathrm{ABC}$ adalah sebagai berikut:

1. Kelas A Persediaan yang memiliki nilai volume tahunan rupiah yang tinggi. Persediaan yang termasuk kelas ini memerlukan perhatian yang tinggi dalam pengadaannya karena berdampak pada biaya yang tinggi dan pemeriksaan dilakukan secara intensif.

2. Kelas B 5 Persediaan dengan nilai tahunan rupiah yang menengah. Dalam kelas ini diperlukan tehnik pengendalian yang moderat.

3. Kelas $\mathrm{C}$ Persediaan yang nilai volume tahunan rupiahnya rendah, yang hanya sekitar 10\% dari total nilai persediaan. Dalam kelas ini diperlukan tehnik pengendalian yang sederhana, pemeriksaan dilakukan sesekali. Sehinga dengan mengetahui kriteria masingmasing kelas, dapat diketahui indicator persediaan tertentu yang harus mendapat perhatian lebih intensif atau lebih serius dibandingkan indikator lainnya. Oleh karena itu dapat diketahui bahwa untuk kegiatan operasi perusahaan memerlukan pengendalian persediaan untuk mengantisipasi resiko terhentinya kegiatan proses produksi atau bahkan hilangnya pelanggan karena kekurangan persediaan bahan baku untuk kegiatan usaha dengan cara menggunakan metode ABC.

UD.Mayong Sari Kabupaten Probolinggo adalah usaha yang bergerak dibidang makanan khususnya pembuatan roti yang sudah eksis selama 25 tahun didirikan pada tanggal 18 Agustus 1991 oleh Bapak Mayong Efendi dan istrinya. Perusahaan ini telah mendapat sertifikat dari Dinas Kesehatan Kabupaten Probolinggo. 


\section{JURNAL EKONOMI DAN MANAJEMEN \\ P-ISSN: 2598-9022/ E-ISSN: 2598-9618 \\ Available at:}

http://e-journal.unipma.ac.id/index.php/capital

P-IRT: 206351301385 ( produksi pangan industri rumah tangga ) dan terdaftar lagi nomer: 037/1328/1995 (penyuluhan keamanan pangan) berlaku sampai dengan 14 Maret 2017 serta Kantor Penanaman Modal dan Perijinan Kabupaten Probolinggo nomor: 517/920.PK/ 426.404/2012 (surat ijin usaha perdagangan kecil) berlaku sampai dengan 19 Desember 2017. Pada tanggal 18 Agustus 1991, perusahaan mulai mencoba membuat roti, pemilik usaha membuat roti dalam tahap permulaan hanya $2 \mathrm{~kg}$ dengan harga per roti Rp 50,00. Dalam tahap permulaan perusahaan ini hanya membuat 1 rasa saja yaitu pisang. Setelah berjalannya waktu UD. Mayong Sari Kabupaten Probolinggo menyediakan berbagai macam rasa yaitu coklat, kacang, susu, dan strawbery.

Selama ini UD. Mayong Sari dari kegiatan usahanya belum menggunakan metode $\mathrm{ABC}$ dalam pengklasifikasian penggunaan bahan baku. Sehingga penulis ingin menerapkan analisis $\mathrm{ABC}$ untuk pengendalian persediaan bahan baku.
Adapun persoalan dalam penelitian ini adalah: Bagaimana Penerapan metode $\mathrm{ABC}$ dalam pengendalian persediaan bahan baku pada UD. Mayong Sari?. Manfaat penelitian ini agar perusahaan dalam mengetahui pengklasifikasian bahan baku yang tergolong kelompok $\mathrm{A}, \mathrm{B}$, dan $\mathrm{C}$.

\section{B. TINJAUAN PUSTAKA}

\section{Persediaan Bahan Baku}

Menurut Heizer dan Render (2010), Persediaan adalah salah satu aset termahal dari banyak perusahaan, mewakili sebanyak 50\% dari keseluruhan modal yang diinvestasikan. Di satu sisi, sebuah perusahaan dapat mengurangi biaya dengan mengurangi persediaan. Di sisi lain, produksi dapat berhenti dan pelanggan menjadi tidak puas ketika sebuah barang tidak tersedia. Sedangkan menurut. Sedangkan menurut Bahagia (2006:7), persediaan adalah suatu sumber daya menganggur (idle resources) yang keberadaannya menunggu proses lebih lanjut. Yang dimaksud proses lebih lanjut disini dapat berupa kegiatan produksi seperti dijumpai 


\section{JURNAL EKONOMI DAN MANAJEMEN \\ P-ISSN: 2598-9022/ E-ISSN: 2598-9618 \\ Available at: \\ http://e-journal.unipma.ac.id/index.php/capital}

pada sistem manufaktur, kegiatan pemasaran seperti yang dijumpai pada sistem distribusi, ataupun kegiatan konsumsi seperti dijumpai pada sistem rumah tangga, perkantoran dan sebagainya, sehingga persediaan merupakan segala macam sumber daya yang belum digunakan yang mempunyai nilai ekonomis dimasa mendatang pada saat aktif.

\section{Pengendalian Persediaan}

Pengendalian perusahaan harus dilaksanakan seefektif mungkin dalam suatu perusahaan untuk mencegah dan menghindari terjadinya kelebihan maupun kekurangan persediaan. Menurut Fahmi (2012:109), manajemen persediaan adalah kemampuan suatu perusahaandalam mengatur dan mengelola setiap kebutuhan barang baik barang mentah, barangsetengah jadi, dan barang jadi agar selalu tersedia baik dalam kondisi pasar yang stabil danberfluktuasi.

Menurut Indrajit dan Djokopranoto (2003), manajemen persediaan (inventory control) atau disebut juga inventory management atau pengendalian tingkat persediaan adalah kegiatan yang berhubungan dengan perencanaan, pelaksanaan, dan pengawasan penentuan kebutuhan material sedemikian rupa sehingga di satu pihak kebutuhan operasi dapat dipenuhi pada waktunya dan di pihak lain investasi persediaan material dapat ditekan secara optimal. Pengendalian persediaan juga berfungsi untuk memastikan ketersediaan suatu barang dan agar perusahaan selalu mempunyai persediaan dalam jumlah yang tepat, pada waktu yang tepat, dan dalam spesifikasi atau mutu yang telah ditentukan sehingga kontinuitas usaha dapat terjamin/tidak terganggu dan biaya yang dikeluarkan untuk mengadakan persediaan minimal (Kusuma, 2009:48)

Mengendalikan persediaan yang tepat bukan hal yang mudah. Apabila jumlah persediaan terlalu besar mengakibatkan timbulnya dana menganggur yang besar (tertanam dalam persediaan), meningkatnya biaya penyimpanan, dan risiko kerusakan barang yang lebih besar. 


\section{JURNAL EKONOMI DAN MANAJEMEN \\ P-ISSN: 2598-9022/ E-ISSN: 2598-9618 \\ Available at: \\ http://e-journal.unipma.ac.id/index.php/capital}

Namun jika persediaan terlalu sedikit mengakibatkan risiko terjadinya kekurangan persediaan (stock out) karena seringkali bahan/barang tidak dapat didatangkan secara mendadak dan sebesar yang dibutuhkan, yang menyebabkan terhentinya proses produksi, tertundanya penjualan bahkan hilangnya pelanggan (Herjanto,2008).

Namun disisi lain, persediaan bahan baku yang terlalu besar akan mengakibatkan: 1.Biaya penyimpanan di gudang, semakin banyak barang yang disimpan maka akan semakin besar biaya penyimpanannya. 2. Risiko kerusakan barang, semakin lama barang tersimpan di gudang maka risiko kerusakan barang semakin tinggi. Barangbarang yang tersimpan lama akan "out of date" atau ketinggalan jaman (Ristono, 2009 : 4).

\section{Pengendalian Persediaan dengan Metode ABC}

ABC Analysis adalah teknik pengendalian persediaan dengan memperhatikan kelompok barang sesuai tingkat kepentingan masing- masing kelompok barang tersebut. Menurut Render dan Heizer (2005:62) Analisis ABC membagi persediaan menjadi tiga kelompok berdasarkan volume tahunan dalam jumlah uang. Dalam ABC Analysis, biasanya barang-barang dikelompokkan menjadi tiga kelas, yaitu A, B, dan C. Kelas A adalah kelompok barang yang sangat penting (nilai penjualan terbesar), kelas B adalah kelompok barang dengan nilai penjualan menengah, dan kelas $\mathrm{C}$ adalah kelompok barang dengan nilai penjualan terkecil.

Untuk mengatasi situasi dimana material yang harus dikendalikan jumlahnya sangatbanyak, adalah bijaksana kalau keputusan pengendalian persediaan dimulai dengan membuatklasifikasi atas material yang ada. Klasifikasi material biasanya dilakukan dengan membuatklasifikasi ABC menurut kaidah Pareto (Ristono, 2009:15). Berdasrkan prinsip Pareto,barang dapat diklasifikasikan menjadi 3 kategori sebagai berikut (Bahagia, 2006:194): 


\section{JURNAL EKONOMI DAN MANAJEMEN \\ P-ISSN: 2598-9022/ E-ISSN: 2598-9618 \\ Available at:}

http://e-journal.unipma.ac.id/index.php/capital

1. Kategori A (80-20):

Terdiri dari jenis barang yang menyerap dana sekitar $80 \%$ dari seluruh modal yangdisediakan untuk inventory dan jumlah jenis barangnya sekitar $20 \%$ dari semua jenis barangyang dikelola.

2. Kategori B (15-30):

Terdiri dari jenis barang yang menyerap dana sekitar $15 \%$ dari seluruh modal yangdisediakan untuk inventory (sesudah kategori A) dan jumlah jenis barangnya sekitar 30\% darisemua jenis barang yang dikelola.

3. Kategori C (5-50):

Terdiri dari jenis barang yang menyerap dana hanya sekitar 5\% dari seluruh modal yangdisediakan unutk inventory (yang tidak termasuk kategori A dan B) dan jumlah jenisbarangnya sekitar $50 \%$ dari semua jenis barang yang dikelola.

Menurut Heizer dan Render (2010:84) Metode analisis ABC merupakan metode yang berguna dalam memfokuskan perhatian manajemen penentuan jenis barang yang paling penting dan perlu diprioritaskan dalam persediaan. Sedangkan menurut Prasetyawan dan Nasution (2008:236) dalam analisis $\mathrm{ABC}$, persediaan suatu perusahaan dibagi menjadi 3 klasifikasi, yaitu: $\mathrm{A}, \mathrm{B}$ dan $\mathrm{C}$ sehingga dikenal sebagai analisis $\mathrm{ABC}$.

\section{Kerangka Pemikiran}

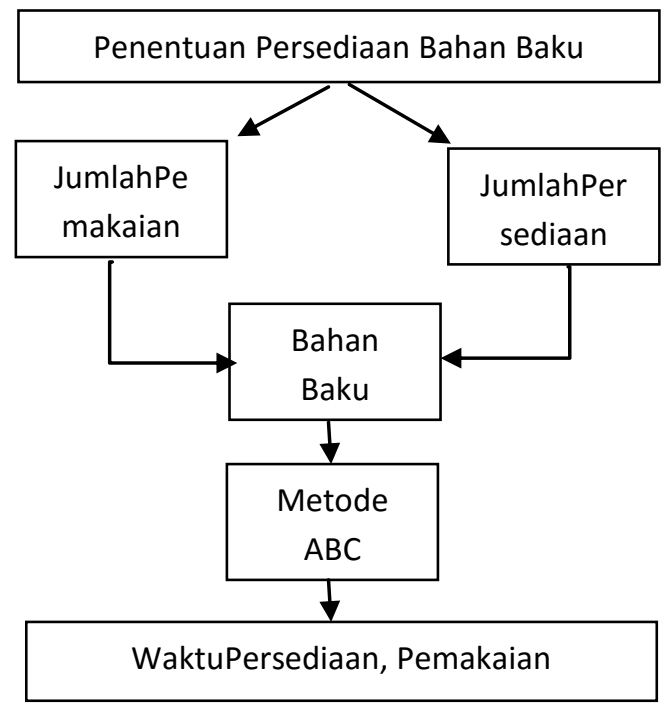

Gambar 1: KerangkaPemikiran

\section{METODE PENELITIAN Jenis Penelitian}

Jenis penelitian yang digunakan oleh peneliti dalam penelitian ini adalah kuantitatif dan deskriptif. Menurut Sekaran (2006:158), metode deskriptif dilakukan untuk mengetahui dan mampu untuk menjelaskan 


\section{JURNAL EKONOMI DAN MANAJEMEN \\ P-ISSN: 2598-9022/ E-ISSN: 2598-9618 \\ Available at:}

http://e-journal.unipma.ac.id/index.php/capital

karakteristik variabel yang diteliti dalam suatu situasi. Penelitian deskriptif memusatkan perhatian kepada pemecahan masalah-masalah aktual sebagaimana adanya pada saat penelitian dilaksanakan.

\section{Pengumpulan Data}

Pada bagian ini, pengumpulan data dilakukan untuk mendapatkan informasi dan data-data yang dibutuhkan dalam rangka menyelesaikan penelitian yang akan dilakukan. Metode pengumpulan data yang digunakan di penelitian ini diperoleh dari:

1. Data Primer

Adapun pengumpulan data primer pada penelitian ini dilakukan melalui sebagai berikut :

a) Wawancara

Salah satu pengumpulan data yang sering diterapkan dan dipandang penting peranannya adalah wawancara. Wawancara merupakan proses tanya jawab atau interaksi antara pihak pencari data atau peneliti selaku pewawancara

(interviewer) dengan responden atau nara sumber yang berposisi sebagai pihak yang diwawancarai (interviewee) (Santosa dan Mulaiwan, 2007:14).

b) Observasi

Observasi adalah kegiatan pengamatan yang dilakukan berlangsung secara seksama dan sistematis, tidak terkesan sambil lalu. Observasi lebih menekankan pada proses pengamatan dimana selanjutnya pengamatan tersebut ditindaklanjuti dengan pencatatan data secara cermat dan sistematis serta dokumentasi yang baik (Santosa dan Mulaiwan, 2007:13)

2. Data Sekunder

Data sekunder merupakan data yang sumbernya secara tidak langsung memberikan data kepada pengumpul data. Data sekunder merupakan struktur data historis mengenai variabel- 


\section{JURNAL EKONOMI DAN MANAJEMEN \\ P-ISSN: 2598-9022/ E-ISSN: 2598-9618 \\ Available at:}

http://e-journal.unipma.ac.id/index.php/capital

variabel yang telah dikumpulkan dan dihimpun sebelumnya oleh pihak lain. Proses mengumpulkan data sekunder dalam penelitian ini dilakukan melalui studi pustaka yaitu menggunakan buku-buku atau jurnal-jurnal yang relevan dengan penelitian dalam memperoleh informasi dan datadata yang dibutuhkan.

\section{Teknik Analisis Data}

Analisis data biasanya mencakup pekerjaan meringkas data yang telah dikumpulkan menjadi salah suatu jumlah yang dapat dikelola, teknik analisis data yang digunakan oleh peneliti adalah dengan menggunakan analisis data kuantitatif. Pada penelitian ini, analisis kuantitatif digunakan karena data penelitian yang digunakan adalah berupa angka-angka. Berikut ini merupakan teknik analisis data yang digunakan oleh peneliti dalam melakukan penelitian ini, yaitu: $A B C$ Analysis.

\section{HASIL PENELITIAN DAN PEMBAHASAN}

\section{Deskripsi Data}

Data kebutuhan bahan baku Pembuatan roti pada UD. Mayong Sari:

Tabel 1

Data Pemakaian Barang 1 tahun

\begin{tabular}{|c|l|c|c|c|}
\hline No & $\begin{array}{c}\text { Jenis } \\
\text { Makanan }\end{array}$ & Satuan & $\begin{array}{c}\text { Kuantitas } \\
\text { Pemakaian } \\
\left(\mathbf{D}_{\mathbf{i}}\right)\end{array}$ & $\begin{array}{c}\text { Harga satuan } \\
\left(\mathbf{P}_{\mathbf{i}}\right)\end{array}$ \\
\hline $\mathbf{( 1 )}$ & \multicolumn{1}{|c}{$\mathbf{( 2 )}$} & $\mathbf{( 3 )}$ & $\mathbf{( 4 )}$ & $\mathbf{( 5 )}$ \\
\hline 1 & $\begin{array}{l}\text { Susu } \\
\text { Bubuk }\end{array}$ & $\mathrm{Kg}$ & 720 & 27.000 \\
\hline 2 & $\begin{array}{l}\text { Selai } \\
\text { Strawberi }\end{array}$ & $\mathrm{Kg}$ & 360 & 31.000 \\
\hline 3 & Pisang & Lirang & 24 & 12.000 \\
\hline 4 & Kacang & $\mathrm{Kg}$ & 1.080 & 24.000 \\
\hline 5 & Coklat & $\mathrm{Kg}$ & 720 & 23.000 \\
\hline 6 & Tepung & $\mathrm{Kg}$ & 18.480 & 6.400 \\
\hline 7 & Gula & $\mathrm{Kg}$ & 2.520 & 16.000 \\
\hline 8 & Telur & $\mathrm{Kg}$ & 768 & 20.000 \\
\hline 9 & Mentega & $\mathrm{Kg}$ & 2.448 & 17.000 \\
\hline
\end{tabular}

Sumber: UD. Mayong Sari Probolinggo

\section{Evaluasi Data}

Pada bagian ini akan dilakukan pengolahan data setelah data-data yang diperlukansudah diperoleh. $\mathrm{Hal}$ ini untuk mengetahui hasil dari tujuan penelitian yang selanjutnya akan dianalisis pada bagian berikutnya. Pengolahan data yang akan dilakukan tersebut adalah sebagai berikut Bahagia (2006:195): 


\section{JURNAL EKONOMI DAN MANAJEMEN \\ P-ISSN: 2598-9022/ E-ISSN: 2598-9618 \\ Available at:}

http://e-journal.unipma.ac.id/index.php/capital

Kategorisasi komponen bahan

baku produk roti dengan

menggunakan metode $A B C$

Analysis

Data yang akan digunakan dalam perhitungan ini adalah data jenis-jenis bahan baku, data jumlah pemakaian tiap jenis bahan baku selama satu tahun dan data harga satuan bahan baku. Adapun langkah untuk melakukan pengelompokan berdasarkan metode $A B C$ Analysis dapat dilakukan dengan cara sebagai berikut:

1. Hitung jumlah penyerapan dana untuk setiap jenis barang per tahun (Mi), yaitu dengan mengalikan antara jumlah pemakaian tiap jenis barang per tahun (Di) dengan harga satuan barang (pi), secara matematis dapat dinyatakan:

$$
\mathrm{Mi}=\mathrm{D}_{\mathrm{i}} \times \mathrm{P}_{\mathrm{i}}
$$

Perhitungan :

$$
\begin{aligned}
& \text { Susu } \quad \mathrm{Mi}=\mathrm{D}_{\mathrm{i}} \times \mathrm{P}_{\mathrm{i}} \\
& \text { Bubuk }=720 \times R p \text {. } \\
& 27.000 \\
& =\mathrm{Rp} \text {. } \\
& 19.440 .000 \\
& \text { Selai } \quad \mathrm{Mi}=\mathrm{D}_{\mathrm{i}} \times \mathrm{P}_{\mathrm{i}} \\
& \text { Strawberi } \quad=360 \times R p .31 .000 \\
& =\mathrm{Rp} 11.160 .000
\end{aligned}
$$

$$
\begin{aligned}
& \text { Pisang } \quad \mathrm{Mi}=\mathrm{D}_{\mathrm{i}} \times \mathrm{P}_{\mathrm{i}} \\
& =24 \times 12.000 \\
& =\operatorname{Rp} 288.000 \\
& \text { Kacang } \quad \mathrm{Mi}=\mathrm{D}_{\mathrm{i}} \times \mathrm{P}_{\mathrm{i}} \\
& =1080 \times 2400 \\
& =\mathrm{Rp} 25.920 .000 \\
& \text { Coklat } \mathrm{Mi}=\mathrm{D}_{\mathrm{i}} \times \mathrm{P}_{\mathrm{i}} \\
& \text { Batang } \quad=720 \times 23000 \\
& =\mathrm{Rp} 16.560 .000 \\
& \text { Tepung } \quad \mathrm{Mi}=\mathrm{D}_{\mathrm{i}} \times \mathrm{P}_{\mathrm{i}} \\
& =18.480 \times 6.400 \\
& =\text { Rp. } 118.272 .000 \\
& \text { Gula } \quad \mathrm{Mi}=\mathrm{D}_{\mathrm{i}} \times \mathrm{P}_{\mathrm{i}} \\
& =2.520 \times 16.000 \\
& =\text { Rp. } 40.320 .000 \\
& \text { Telur } \quad \mathrm{Mi}=\mathrm{D}_{\mathrm{i}} \times \mathrm{P}_{\mathrm{i}} \\
& =768 \times 20.000 \\
& =\text { Rp 15.360.000 } \\
& \text { Mentega } \mathrm{Mi}=\mathrm{D}_{\mathrm{i}} \times \mathrm{P}_{\mathrm{i}} \\
& =2.448 \times 17.000 \\
& =\text { Rp. 41.616.000 }
\end{aligned}
$$

2. Hitung jumlah total penyerapan dana untuk semua jenis barang, secara matematis dapat dinyatakan:

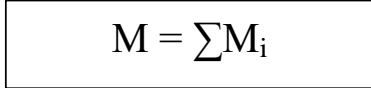

Perhitungan :

M $\sum \mathrm{M}_{\mathrm{i}}$

$$
\begin{aligned}
& 19.440 .000+11.160 .000+ \\
& 288.000+25.920 .000+ \\
& 16.560 .000+118.272 .000+ \\
& 40.320 .000+15.360 .000+ \\
& 41.616 .000 \\
& =288.936 .000
\end{aligned}
$$

3. Hitung persentase penyerapan dana untuk setiap jenis barang $(\mathrm{Pi})$, secara matematis dapat dinyatakan: 


\section{JURNAL EKONOMI DAN MANAJEMEN \\ P-ISSN: 2598-9022/ E-ISSN: 2598-9618 \\ Available at:}

http://e-journal.unipma.ac.id/index.php/capital

$$
\mathrm{P}_{\mathrm{i}}=\frac{M_{i}}{M} \times 100 \%
$$

Perhitungan:

Susu

$$
\begin{aligned}
\mathrm{Pi} & =\frac{M_{i}}{M} \times 100 \% \\
& =\frac{19.440 .000}{288.936 .000} \\
\mathrm{x} 100 \% & =6,73 \%
\end{aligned}
$$

$\begin{aligned} & \text { Selai } \\ & \text { strowberi }\end{aligned} \quad \mathrm{Pi}=\frac{M_{i}}{M} \times 100 \%$

$$
\begin{aligned}
& = \\
& \frac{11.160 .000}{288.936 .000} \times 100 \% \\
& =3,86 \%
\end{aligned}
$$

Pisang $\quad \mathrm{Pi}=\frac{M_{i}}{M} \times 100 \%$

$$
\begin{aligned}
& =\frac{288.000}{288.936 .000} \\
& \times 100 \% \\
& =0,11 \%
\end{aligned}
$$

Kacang $\quad \mathrm{Pi}=\frac{M_{i}}{M} \times 100 \%$

$$
\begin{aligned}
& =\frac{25.920 .000}{288.936 .000} \\
& \times 100 \% \\
& \quad=8,97 \%
\end{aligned}
$$

Coklat

$$
\mathrm{Pi}=\frac{M_{i}}{M} \times 100 \%
$$

$$
\begin{aligned}
& =\frac{16.560 .000}{288.936 .000} \\
\mathrm{x} 100 \% & =5,73 \% \\
\text { Tepung } \quad \mathrm{Pi} & =\frac{M_{i}}{M} \times 100 \% \\
& =\frac{118.272 .000}{288.936 .000} \\
\mathrm{x} 100 \% & =40,93 \% \\
\text { Gula } \quad \mathrm{Pi} & =\frac{M_{i}}{M} \times 100 \%
\end{aligned}
$$

$$
\begin{aligned}
&= \frac{40.320 .000}{288.936 .000} \\
& \mathrm{x} 100 \% \\
&=13,95 \% \\
& \mathrm{Pi}=\frac{M_{i}}{M} \times 100 \%
\end{aligned}
$$

Telur

$$
\begin{aligned}
&= \frac{15.360 .000}{288.936 .000} \\
& \mathrm{X} 100 \%
\end{aligned}
$$

$$
\begin{aligned}
& =5,32 \% \\
\text { Mentega } \quad \mathrm{Pi} & =\frac{M_{i}}{M} \times 100 \%
\end{aligned}
$$

$$
\begin{gathered}
=\frac{41.616 .000}{288.936 .000} \\
\times 100 \% \\
=14,40 \%
\end{gathered}
$$

4. Hitung persentase setiap jenis item, secara matematis dapat dinyatakan:

$$
\mathrm{I}_{\mathrm{i}}=\frac{1}{N} \times 100 \%
$$

Dimana $\mathrm{N}$ adalah jumlah jenis item barang.

Perhitungan:

$$
\text { Ii } \begin{aligned}
& =\frac{1}{N} \times 100 \% \\
& =\frac{1}{9} \times 100 \% \\
& =11,11 \%
\end{aligned}
$$

5. Urutkan persentase penyerapan dana sesuai dengan urutan besarnya persentase penyerapan dana, dimulai dari persentase penyerapan dana terbesar sampai dengan yang terkecil.

6. Hitung nilai kumulatif persentase penyerapan dana 


\section{JURNAL EKONOMI DAN MANAJEMEN \\ P-ISSN: 2598-9022/ E-ISSN: 2598-9618 \\ Available at:}

http://e-journal.unipma.ac.id/index.php/capital

dan nilai kumulatif persentase

jenis barang berdasarkan

urutan yang diperoleh pada

langkah 5.

7. Tentukan kategorisasi barang berdasarkan prinsip Pareto. Berdasarkan prinsip Pareto, barang dapat diklasifikasikan menjadi 3 kategori sebagai berikut (Bahagia, 2006:194)

a. Kategori A (80-20):

Yakni terdiri dari
jenis barang yang
menyerap dana sekitar
$80 \%$ dari seluruh modal
yang disediakan untuk
inventori dan jumlah jenis
barangnya sekitar 20\%
dari semua jenis barang
yang dikelola.

b. Kategori B (15-30):

Yakni terdiri dari jenis barang yang menyerap dana sekitar $15 \%$ dari seluruh modal yang disediakan untuk inventori

(sesudah

kategori A) dan jumlah jenis barangnya sekitar
$30 \%$ dari semua jenis barang yang dikelola.

c. Kategori C (5-50):

Yakni terdiri dari jenis barang yang menyerap dana hanya sekitar 5\% dari seluruh modal yang disediakan untuk inventori (yang tidak termasuk kategori A dan B) dan jumlah jenis barangnya sekitar $50 \%$ dari semua jenis barang yang dikelola.

Tabel 2.

Nilai Persentase Dana Setiap Jenis Bahan Baku (Dana dalam Rupiah dan Persentase dalam \%)

\begin{tabular}{|c|c|c|c|c|c|c|}
\hline \multicolumn{7}{|c|}{ Persentase dalam \%) } \\
\hline $\begin{array}{l}\mathbf{N} \\
\mathbf{o}\end{array}$ & $\begin{array}{c}\text { Jenis } \\
\text { Bara } \\
\text { ng }\end{array}$ & $\begin{array}{l}\text { Sa } \\
\text { tu } \\
\text { an }\end{array}$ & $\begin{array}{c}\text { Kuanti } \\
\text { tas } \\
\text { Pemak } \\
\text { aian } \\
\left(D_{i}\right) \\
\end{array}$ & $\begin{array}{c}\text { Harga } \\
\text { Satuan } \\
\text { Baran } \\
\text { g }\left(P_{i)}\right.\end{array}$ & $\begin{array}{c}\text { Nilai } \\
\text { Penera } \\
\text { pan } \\
\text { Dana } \\
\left(\mathbf{M}_{\mathbf{i})}\right. \\
\end{array}$ & $\begin{array}{c}\text { Penyer } \\
\text { apan } \\
\text { Dana } \\
\left(\mathbf{P}_{\mathrm{i}}\right)\end{array}$ \\
\hline 1 & $\begin{array}{l}\text { Susu } \\
\text { Bubu } \\
\mathrm{k} \\
\end{array}$ & $\mathrm{Kg}$ & 720 & 27.000 & $\begin{array}{c}19.440 . \\
000\end{array}$ & $6,73 \%$ \\
\hline 2 & $\begin{array}{l}\text { Selai } \\
\text { Strawb } \\
\text { ery }\end{array}$ & $\mathrm{Kg}$ & 360 & 31.000 & $\begin{array}{c}11.160 . \\
000\end{array}$ & $3,86 \%$ \\
\hline 3 & $\begin{array}{l}\text { Pisan } \\
\mathrm{g}\end{array}$ & $\begin{array}{c}\text { Lir } \\
\text { an } \\
\mathrm{g}\end{array}$ & 24 & 12.000 & $\begin{array}{c}28.803 . \\
000\end{array}$ & $0,11 \%$ \\
\hline 4 & $\begin{array}{l}\text { Kacan } \\
\mathrm{g}\end{array}$ & $\mathrm{Kg}$ & 1.080 & 24.000 & $\begin{array}{c}25.920 . \\
000\end{array}$ & $8,97 \%$ \\
\hline 5 & $\begin{array}{l}\text { Coklat } \\
\text { Batang }\end{array}$ & $\mathrm{Kg}$ & 720 & 23.000 & $\begin{array}{c}16.560 . \\
000\end{array}$ & $5,73 \%$ \\
\hline 6 & $\begin{array}{l}\text { Tepun } \\
\mathrm{g}\end{array}$ & $\mathrm{Kg}$ & 18.480 & 6.400 & $\begin{array}{c}118.27 \\
2.000 \\
\end{array}$ & $\begin{array}{c}40,93 \\
\%\end{array}$ \\
\hline 7 & Gula & $\mathrm{Kg}$ & 2.520 & 16.000 & $\begin{array}{c}40.320 . \\
000\end{array}$ & $\begin{array}{c}13,95 \\
\%\end{array}$ \\
\hline 8 & Telur & $\mathrm{Kg}$ & 768 & 20.000 & $\begin{array}{c}15.360 . \\
000\end{array}$ & $5,32 \%$ \\
\hline 9 & $\begin{array}{l}\text { Mente } \\
\text { ga }\end{array}$ & $\mathrm{Kg}$ & 2.448 & 17.000 & $\begin{array}{c}41.616 . \\
000\end{array}$ & $\begin{array}{c}14,40 \\
\%\end{array}$ \\
\hline
\end{tabular}

Sumber: Data diolah 


\section{JURNAL EKONOMI DAN MANAJEMEN \\ P-ISSN: 2598-9022/ E-ISSN: 2598-9618 \\ Available at:}

http://e-journal.unipma.ac.id/index.php/capital

Setelah nilai presentase penyerapan dana setiap jenis bahan baku dihitung, setelah itu melakukan pengurutan sesuai besarnya persentase penyerapan dana, dimulai dari persentase penyerapan dana terbesar sampai dengan yang terkecil. Setelah itu melakukan perhitungan nilai kumulatif persentase penyerapan dana dan melakukan kategorisasi barang berdasarkan prinsip pareto. Dari perhitungan yang telah dilakukan maka dapat disajikan presentase kumulatif penyerapan dana pada UD.Mayong Sari pada tabel sebagai berikut:

Tabel 3. Presentase Kumulatif

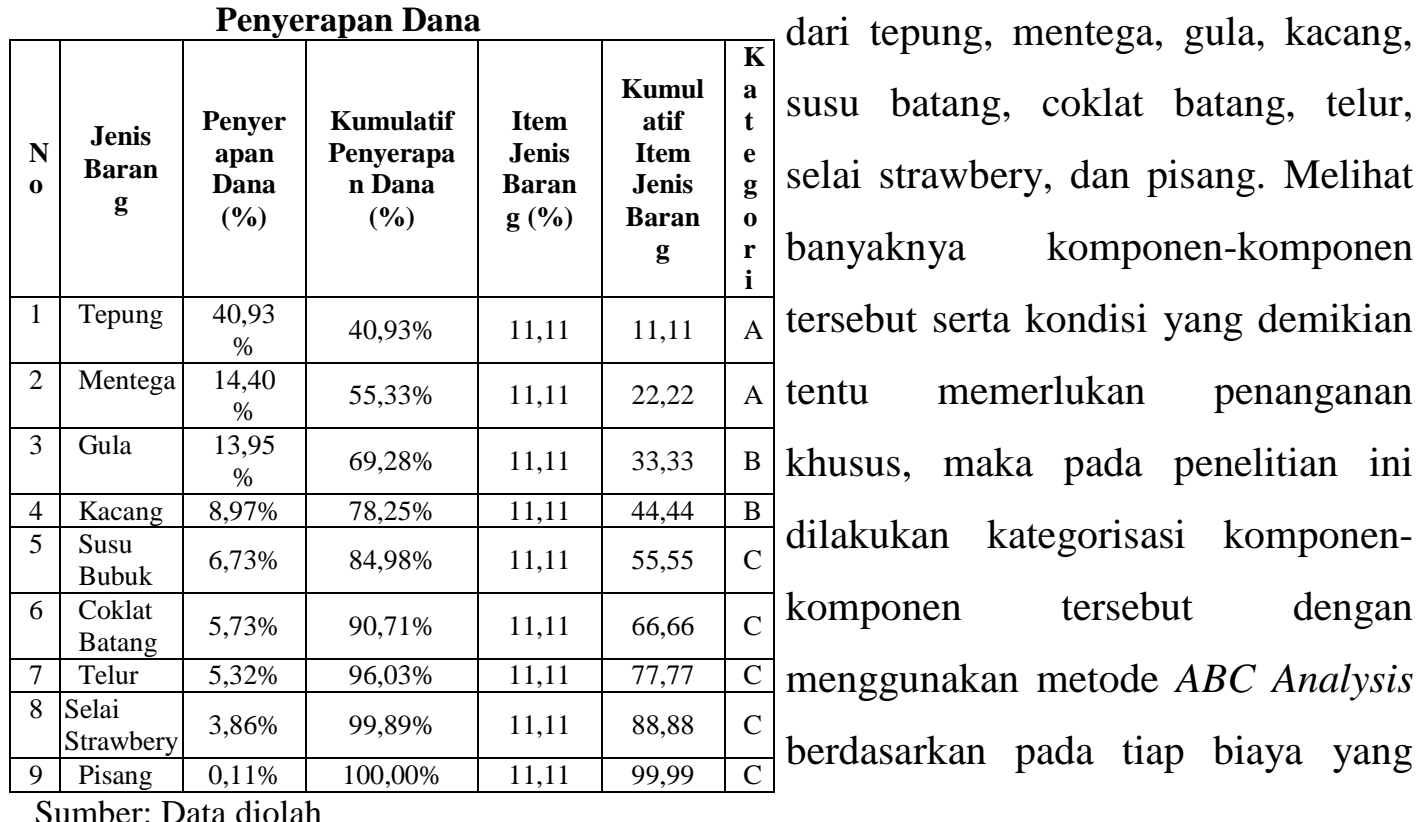

Analisis Klasifikasi ABC pada

Bahan Baku Roti Manis UD.

Mayong Sari

Setelah melakukan pengolahan data berdasarkan prinsip $\mathrm{ABC}$, dapat diperoleh kategori bahan baku sebagai berikut:

Kategori A : Tepung dan Mentega Kategori B : Gula dan Kacang Kategori C :Susu bubuk, Coklat batang, Telur, Selai Strawbery dan Pisang.

\section{Pembahasan}

Jika dilihat secara keseluruhan, jenis bahan baku dalam membuat satu unit produk Roti Manis terdiri dari 9 jenis komponen yang terdiri dari tepung, mentega, gula, kacang,

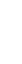




\section{JURNAL EKONOMI DAN MANAJEMEN \\ P-ISSN: 2598-9022/ E-ISSN: 2598-9618 \\ Available at: \\ http://e-journal.unipma.ac.id/index.php/capital}

dikeluarkan dalam melakukan

pembelian.

Pengelompokan ini dilakukan untuk menentukan komponenkomponen apa saja yang membutuhkan pengendalian lebih dalam serta yang paling penting untuk perusahaan. Untuk itu perlu diperhatikan secara lebih baik. Dengan adanya penerapan metode $\mathrm{ABC}$ ini diharapkan dapat membantu UD.Mayong Sari dalam memilih dan mengklasifikasikan jenis komponen bahan baku yang mana lebih utama dari pada komponen bahan baku yang lainnya.

Berdasarkan ABC Analysis yang diterapkan, maka komponenkomponen tersebut dapat dikategorikan dalam 3 kategori yaitu:

1. Kategori A terdiri dari 2 item yaitu Tepung dan Mentega.

Kedua komponen tersebut dikategorikan kelas A karena persentase kumulatif penyerapan dana kurang dari atau sama dengan $80 \%$, sedangkan presentase kumulatif item jenis barang kurang dari atau lebih dari $20 \%$.
2. Kategori B terdiri dari 2 item yaitu Gula dan Kacang.

Kedua jenis komponen karena presentase kumulatif item jenis barang kurang dari atau lebih dari $30 \%$

3. kategori $\mathrm{C}$ terdiri dari 5 jenis komponen yaitu Susu batang, Coklat batang, Telur, Selai strawbery dan Pisang.

Kelima komponen tersebut dikategorikan kelas C karena memiliki persentase kumulatif item jenis barang lebih dari $50 \%$

Komponen-komponen yang termasuk dalam kategori A ini membutuhkan pengendalian yang lebih besar jika dibandingkan dengan kategori B dan C. Sehingga agar tidak memunculkan beban biaya yang besar pada kategori A, yang merupakan kategori yang paling penting dalam proses produksi ini, maka pengendaliannya perlu diperhatikan secara lebih baik.

Perusahaan UD. Mayong Sari diharapakan dapat menerapkan analisis $\mathrm{ABC}$ dalam perencanaan persediaan bahan baku. Karena 


\section{JURNAL EKONOMI DAN MANAJEMEN \\ P-ISSN: 2598-9022/ E-ISSN: 2598-9618 \\ Available at: \\ http://e-journal.unipma.ac.id/index.php/capital}

dengan analisis $\mathrm{ABC}$ ini perusahaan dapat membedakan mana bahan baku yang memiliki prioritas utama yang lebih khusus dan memerlukan pengendalian yang lebih baik.

\section{E. KESIMPULAN}

Berdasarkan hasil penelitian yang telah dilakukan maka dapat disimpulkan sebagai berikut:

1. Berdasarkan prinsip klasifikasi $\mathrm{ABC}$ bahwa tingkat kepentingan barang dapat ditinjau dari tigkat kecepatan pemakaian, atau tingkat keuntungan yang dapat diperoleh dan berdasarkan tingkat penyerapan modal. Sehingga bahan baku yang masuk kategori A yaitu paling menyerap dana terbesar adalah tepung dan mentega.

2. Jenis bahan baku dalam membentuk satu unit produk roti manis ini terdiri dari 9 jenis komponen. Berdasarkan $A B C$ Analysis yang diterapkan, maka komponen-komponen tersebut dapat dikategorikan dalam 3 kategori yaitu kategori
A, kategori B dan kategori C Dari 9 jenis komponen yang dihitung, berdasarkan Tabel 3 maka yang masuk dalam kategori A berjumlah 2 jenis komponen, kategori B berjumlah 2 jenis komponen dan 5 jenis komponen yang masuk dalam kategori $\mathrm{C}$.

\section{Saran}

Dengan adanya penelitian ini diharapkan "UD.Mayong Sari” dapat lebih memperhatikan bahan baku dengan kategori kelas A yang memerlukan penanganan secara khusus karena kategori kelas A merupakan bahan baku yang menyerap dana paling besar dibandingkan dengan kategori kelas B dan C. Dimana kategori kelas A merupakan bahan baku yang paling penting dalam proses produksi, maka pengendaliannya perlu diperhatikan secara lebih.

\section{Keterbatasan Penelitian}

Dari proses penelitian dari awal sampai akhir, peneliti juga mendapat kendala yang dihadapi 


\section{JURNAL EKONOMI DAN MANAJEMEN \\ P-ISSN: 2598-9022/ E-ISSN: 2598-9618 \\ Available at: \\ http://e-journal.unipma.ac.id/index.php/capital}

selama proses penelitian yaitu data yang diberikan oleh UD. Mayong Sari masih belum begitu akurat karena metode yang digunakan dalam perencanaan bahan baku masih menggunakan metode perkiraan sehingga data yang diperoleh belum tentu tepat.

\section{DAFTAR PUSTAKA}

Bahagia, Senator Nur.2006. Sistem Inventori. Bandung: Penerbit ITB.

Indrajit RE, Djokopranoto R. 2003. Manajemen persediaan barang umum dan suku cadang untuk keperluan pemeliharaan perbaikan dan operasi. Jakarta: PT. Grasindo.

Kusuma, Hendra. 2009. Manajemen Produksi: Perencanaan dan Pengendalian Produksi. Edisi 4. Yogyakarta : Penerbit Andi.

Heizer, Jay dan Render, Barry. 2010. Manajemen Operasi. Edisi 9. Diterjemahkan oleh: Sungkono, Chriswan. Jakarta: Salemba Empat.

Nasution, Arman Hakim dan Prasetyawan Yudha. 2008. Perencanaan dan Pengendalian Produksi, Edisi Pertama, Yogyakarta:Graha Ilmu.
Fahmi, Irham (2012). Manajemen Produksi dan Operasi. Bandung: Alfabeta.

Ristono,Agus. 2009. Manajemen Persediaan.Yogyakarta: Graha Ilmu.

Herjanto, Eddy. 2008. Manajemen Operasi. Edisi Ketiga. Jakarta: Grasindo.

Sekaran, Uma (2006). Metodologi Penelitian untuk Bisnis (Edisi 4). Jakarta: Salemba Empat.

Santosa, Purbayu Budi dan Mulaiwan Hamdani. 2007. Statistika Deskriptif dalam Bidang Ekonomi dan Niaga. Semarang: ERLANGGA. 